\title{
An Integrated Quantitative Proteomics and Systems Biology Approach to Explore Synaptic Protein Profile Changes During Morphine Exposure
}

\author{
Steven D Stockton $\mathrm{Jr}^{1}$ and Lakshmi A Devi ${ }^{*, 1}$ \\ ${ }^{1}$ Department of Pharmacology and Systems Therapeutics and Friedman Brain Institute, Icahn School of Medicine at Mount \\ Sinai, New York, NY, USA
}

Morphine is a classic analgesic for the treatment of chronic pain. However, its repeated use is known to produce tolerance, physical dependence, and addiction; these properties limit its long-term therapeutic use and this has led to a quest for therapeutics without these unwanted side effects. Understanding the molecular changes in response to long-term use of morphine is likely to aid in the development of novel therapeutics for the treatment of pain. Studies examining the effects of chronic morphine administration have reported alterations in gene expression, synapse morphology, and synaptic transmission implying changes in synaptic protein profile. To fully understand the changes in protein profiles, proteomic techniques have been used. Studies using two-dimensional gel electrophoresis of various brain regions combined with mass spectrometry have found alterations in the levels of a number of proteins. However, neither the changes in brain regions relevant to morphine effects nor changes in the abundance of synaptic proteins have been clearly delineated. Recent studies employing subcellular fractionation to isolate the striatal synapse, combined with quantitative proteomics and graph theoryinspired network analyses, have begun to quantify morphine-regulated changes in synaptic proteins and facilitate the generation of networks that could serve as targets for the development of novel therapeutics for the treatment of chronic pain. Thus, an integrated quantitative proteomics and systems biology approach can be useful to identify novel targets for the treatment of pain and other disorders of the brain.

Neuropsychopharmacology Reviews (2014) 39, 88-103; doi:10.1038/npp.20 13.227; published online 23 October 2013

Keywords: opiate; pain; addiction; synaptic plasticity; proteomics; $\mu$-opioid receptor

\section{MORPHINE AND OPIOID RECEPTOR SIGNALING}

Morphine is currently the gold standard for the management of severe, acute pain in the clinical setting. Morphine is also the analgesic of choice for a variety of chronic, nonterminal pain syndromes (Berland and Rodgers, 2012). It is important to note that a number of additional applications for morphine beyond analgesia have also been documented. As a consequence of the ability of morphine to reduce gut motility and inhibit intestinal peristalsis, morphine has been shown to be a potent antidiarrheal agent (Calignano et al, 1991). Moreover, morphine also exhibits

*Correspondence: Dr LA Devi, Department of Pharmacology and Systems Therapeutics, Mount Sinai School of Medicine, 19-84 Annenberg Building, One Gustave L Levy Place, New York, NY 10029, USA, Tel: +1 212241 8345, Fax: +1 212996 7214,

E-mail: lakshmi.devi@mssm.edu

Received 9 July 2013; accepted 10 July 2013; accepted article preview online 18 September 2013 excellent antitussive properties (Meyer, 2008). Although several uses for morphine have been identified, its use has been restricted to the treatment of severe pain predominantly as a consequence of several critical adverse effects associated with chronic exposure to these compounds.

The majority of the morphine effects are brought about by activating opioid receptors that belong to a family of pertussis toxin-sensitive $G_{\alpha_{i}} / G_{\alpha o}$ protein-coupled receptors (Hsia et al, 1984; Taussig et al, 1993). Following acute morphine administration, activation of opioid receptors results primarily in the inhibition of synaptic transmission, ultimately leading to the well-characterized analgesia induced by morphine. As a result of their $G_{i} / G_{o}$ coupling, activation of opioid receptors by acute administration of morphine or other opiates leads to an inhibition of adenylyl cyclase activity (Duman et al, 1988; Taussig et al, 1993), and consequently to a decrease in cyclic AMP (cAMP) levels (Minneman and Iversen, 1976; Al-Hasani and Bruchas, 2011) and to decreased activity of protein kinase A (PKA). In addition, acute administration of morphine or other 
opiates results in diminished presynaptic $\mathrm{Ca}^{2+}$ conductance (Lovinger et al, 2003; Lovinger, 2010), increased $\mathrm{K}^{+}$conductance, and hyperpolarization of the pre- and postsynaptic terminals (Faber and Sah 2004), along with an overall reduction in both neurotransmitter release and postsynaptic neurotransmitter signaling (Law et al, 2000).

Chronic exposure to morphine and other opiates leads to a phenomenon termed adenylyl cyclase (AC) superactivation, and results in enhanced activity of both $\mathrm{AC}$ and PKA across multiple regions of the central nervous system (Duman et al, 1988). Currently, it is thought that the facilitated activity of AC, PKA, and CAMP in response to chronic morphine exposure, while representing a homeostatic compensatory mechanism (Nestler, 1996; Al-Hasani and Bruchas, 2011), may also contribute to the etiology of opiate addiction (Terwilliger et al, 1991; Nestler, 2001). This is thought to be because of changes in gene expression; chronic exposure to morphine has been shown to induce the activity of a number of transcription factors. This suggests that the persistent use of morphine and other opiate compounds has the ability to alter gene transcription, and that the phenomenon of addiction is likely associated with persistent alterations of gene expression (Nestler, 2004; Chao and Nestler, 2004). Although several studies have explored global changes in gene expression in response to chronic morphine administration, relatively few studies have examined changes in the local protein abundance at the synapse and/or dendrites. This is important because chronic administration of virtually any drug with a liability for abuse has been shown to lead to alterations in synaptic plasticity throughout the reward circuitry of the nervous system (Russo et al, 2010).

\section{NEUROPROTEOMICS EXPLORATIONS OF MORPHINOME}

Emerging proteomics approaches provide a global and unbiased snapshot of alterations in the proteome under investigation in response to a specific drug treatment. Moreover, utilizing an unbiased methodology also generates data with respect to the enhanced or reduced expression of proteins in response to the physiological perturbation applied. Two-dimensional electrophoresis (2-DE) represents the most common approach utilized to assess morphine-regulated alterations in protein expression (Table 1) (Kim et al, 2004, 2005; Li et al, 2006, 2009; Shui et al, 2007; Yang et al, 2007; Suder et al, 2009; Tan et al, 2010; Lin et al, 2011; Bu et al, 2012; Song et al, 2012; Wei et al, 2013). One of the earliest studies that utilized this approach studied alterations in the morphinome resulting from behavioral sensitization induced as a consequence of 14 days of intermittent exposure to morphine ( $\mathrm{Li}$ et al, 2006) (Morphinome refers to a set of proteins at a brain region affected by morphine treatment.) Animals in this study were killed $24 \mathrm{~h}$ subsequent to the final injection of morphine and the nucleus accumbens (NAc) of each animal was rapidly dissected, homogenized, and subjected to 2-DE analysis. The authors reported that an average of 1500 spots per gel were visualized, but only 22 exhibited significant (ie, >1.5-fold) differences between morphine and saline conditions, 15 of which were successfully characterized via MALDI-TOF MS. Although three of the observed proteins were known to be synaptic in origin ( $\beta$-synuclein, Lin-7, and synapsin), the others were cytoskeletal in origin, contributed to synaptic transmission or energy metabolism, or interestingly were involved in the functioning of the ubiquitin-proteasome system (ubiquitin C-terminal hydrolase L-1). Interestingly, this latter finding suggests a role for protein degradation in the genesis of behavioral sensitization to morphine.

Another study that utilized 2-DE investigated the effects of chronic $(2 \times /$ day for 5 days) intrathecal injections of morphine on global protein expression in the spinal cord (Shui et al, 2007). At $30 \mathrm{~min}$ after the final morphine injection, morphine-treated and control rats were tested for development of tolerance to morphine by application of radiant heat to the hind paw of each animal and recording withdrawal latencies. Immediately following this test, segments of the spinal cord containing the lumbar enlargements were isolated, homogenized, and subjected to 2-DE. A total of eight proteins exhibited differential expression between the morphine- and saline-treated groups. These were either cytoskeletal in origin, involved in targeting and trafficking of glutamate and opioid receptors, or were involved in oxidative stress. Interestingly, the chaperone protein HSP70 was observed to be significantly downregulated, whereas $\mathrm{PKC} \gamma$ exhibited a time-dependent upregulation. In light of confounding evidence that suggests a role for PKC in the development of morphine tolerance and dependence (Granados-Soto et al, 2000; Zeitz et al, 2001), a more recent study (Song et al, 2012) specifically investigated the effects of persistent intrathecal morphine administration $(2 \times /$ day for 6 days $)$ on $\mathrm{PKC} \gamma$-related proteins in the L4-L5 spinal cord of rats following a local knockdown of $\mathrm{PKC} \gamma \quad(\mathrm{PKC} \gamma-\mathrm{k} / \mathrm{d})$ via lentiviral $\operatorname{shPKC} \gamma$. In this study, a total of 18 spots exhibited differential regulation between wild-type and $\mathrm{PKC} \gamma-\mathrm{k} / \mathrm{d}$ tolerant rats, of which 13 proteins involved in cytoskeletal organization, oxidative stress, neurotrophic factors, ion metabolism, cell signaling, and protein chaperones were identified via MALDITOF-MS.

Further studies sought to understand alterations in the morphinome in response to morphine-induced conditioned place preference (CPP) in both the prefrontal cortex (Yang et al, 2007) and the amygdala (Wolters et al, 2001). In the first of these studies (Yang et al, 2007), 2-DE + MALDI-TOF MS was used to elucidate the expression of PSD-related proteins in the PFC during three phases of morphine CPPacquisition, extinction, and reinstatement. In total, 58 proteins were observed to be differentially regulated by morphine across these three phases of morphine-induced CPP: 21 during the acquisition phase, 14 during extinction, and 23 during the reinstatement phase. These 58 identified 
TABLE 1 Proteomic Investigations of Morphine-Regulated Changes in Protein Expression

\begin{tabular}{|c|c|c|c|c|c|c|c|c|c|c|}
\hline Reference & Species & $\begin{array}{l}\text { Region of } \\
\text { interest }\end{array}$ & Fraction & Morphine treatment & $\begin{array}{l}\text { Duration of } \\
\text { treatment }\end{array}$ & $\begin{array}{c}\text { Route of } \\
\text { administration }\end{array}$ & $\begin{array}{l}\text { Behavioral } \\
\text { phenotype }\end{array}$ & $\begin{array}{l}\text { Proteomic } \\
\text { methods }\end{array}$ & $\begin{array}{l}\text { No. of altered } \\
\text { proteins }\end{array}$ & Functional groupings \\
\hline Prokai et al, 2005 & $\begin{array}{l}\text { Sprague-Dawley } \\
\text { rat }\end{array}$ & $\begin{array}{c}\text { Forebrain } S \\
\text { cortex }\end{array}$ & Synaptic membranes & $1.8 \mathrm{mg} / \mathrm{kg} / \mathrm{h}$ & 7 Days & SC (osmotic pump) & Dependence & $\begin{array}{c}\text { ICAT + LC/ESI-MSI } \\
\text { MS }\end{array}$ & 27 & $\begin{array}{l}\mathrm{Na}^{+} / \mathrm{K}^{+} / \mathrm{ATPase} \alpha \text {-subunit, } \\
\text { nonerythroid spectrin } \alpha-\|\end{array}$ \\
\hline Kim et al, 2005 & $\begin{array}{c}\text { Sprague-Dawley } \\
\text { rat }\end{array}$ & Frontal cortex & Total homogenate & $26 \mathrm{nmol} / \mu \mathrm{l} / \mathrm{h}$ & 3 Days & ICV (osmotic pump) & Dependence & $\begin{array}{c}\text { 2-DE + MALDI } \\
\text { TOF MS }\end{array}$ & 40 & $\begin{array}{l}\text { Enzymes, Cyto-skeletal Proteins, } \\
\text { Cell Signaling Proteins }\end{array}$ \\
\hline Li et al, 2006 & Wistar rat & $\begin{array}{c}\text { Nucleus } \\
\text { accumbens }\end{array}$ & Total homogenate & $10 \mathrm{mg} / \mathrm{kg} / \mathrm{day}$ & 14 Days & SC & $\begin{array}{l}\text { Behavioral } \\
\text { sensitization }\end{array}$ & $\begin{array}{c}2-D E+\text { MALDI } \\
\text { TOF MS }\end{array}$ & 15 & $\begin{array}{l}\text { Energy metabolism, cytoskeleton, } \\
\text { ubiquitination/proteasome pathway, } \\
\text { synaptic trans-mission }\end{array}$ \\
\hline Moron et al, 2007 & $\begin{array}{l}\text { C57/BL/6) Bom } \\
\text { mouse }\end{array}$ & Hippocampus & PSD & $\begin{array}{l}\text { Escalating } \\
\text { morphine: } \\
5-15 \mathrm{mg} / \mathrm{kg}\end{array}$ & 2 Days & $\mathbb{P}$ & Tolerance & $\begin{array}{c}\text { 2-DE (DIGE) }+ \\
\text { ESI-MS/MS }\end{array}$ & 102 & $\begin{array}{l}\text { Signaling, trafficking, cytoskeletal } \\
\text { proteins }\end{array}$ \\
\hline Shui et al, 2007 & $\begin{array}{l}\text { Sprague-Dawley } \\
\text { rat }\end{array}$ & $\begin{array}{l}\text { Lumbar spinal } \\
\text { cord }\end{array}$ & Total homogenate & $20 \mathrm{mg} / \mid \mathrm{l} 0 \mu \mathrm{I}$ & $\begin{array}{l}2 \times / \text { day } \\
\text { for } 5 \text { days }\end{array}$ & IC & Tolerance & $\begin{array}{l}\text { 2-DE }+ \\
\text { MALDI TOF MS }\end{array}$ & 8 & Receptor trafficking, oxidative stress \\
\hline Yang et al, 2007 & Sprague-Dawley rat & $\begin{array}{l}\text { Prefrontal } \\
\text { cortex }\end{array}$ & PSD & $\begin{array}{c}10 \mathrm{mg} / \mathrm{kg} \text { (training/test) } \\
2.5 \mathrm{mg} / \mathrm{kg} \text { (priming } \\
\text { phase) }\end{array}$ & - & $\mathbb{P}$ & $\begin{array}{l}\text { Conditioned } \\
\text { place preference }\end{array}$ & $\begin{array}{c}\text { 2-DIGE }+ \\
\text { MALDI TOF MS }\end{array}$ & $\begin{array}{l}58 \text { (variable } \\
\text { by phase } \\
\text { of CPP) }\end{array}$ & $\begin{array}{l}\text { Energy metabolism, signal transduction, } \\
\text { synaptic transmission, cytoskeletal } \\
\text { proteins, local synaptic protein } \\
\text { synthesis machinery, chaperone } \\
\text { proteins }\end{array}$ \\
\hline Li et al, 2009 & Wistar rat & $\begin{array}{l}\text { Spinal cord } \\
\text { DRG }\end{array}$ & Total homogenate & $\begin{array}{l}\text { Escalating } \\
\text { morphine: } \\
5-40 \mathrm{mg} / \mathrm{kg}\end{array}$ & $\begin{array}{l}1 \mathrm{~m} / / \mathrm{kg}-2 \times 1 \\
\text { day for } 28 \text { days }\end{array}$ & SC & Dependence & $\begin{array}{c}\text { 2-DE }+ \\
\text { ESI-Q-TOF-MS/MS }\end{array}$ & 12 & $\begin{array}{l}\text { Energy metabolism, protein } \\
\text { degradation, signaling, cytoskeletal } \\
\text { proteins }\end{array}$ \\
\hline Suder et al, 2009 & Wistar rat & $\begin{array}{l}\text { Astrocyte } \\
\text { culture }\end{array}$ & Total homogenate & $10 \mu \mid$ & 5 Days & Growth medium & N/A & $\begin{array}{c}\text { 2-DE }++ \\
\text { nano-LC/ESI-MS/MS }\end{array}$ & 10 & $\begin{array}{l}\text { Cytoskele-tal and associated chaperone } \\
\text { proteins, biosynthesis-related proteins, } \\
\text { others }\end{array}$ \\
\hline Tan et al, 2010 & $\begin{array}{l}\text { New Zealand } \\
\text { white rabbit }\end{array}$ & Myocardium & Unspecified & 3 mg/kg (bolus) & Unspecified & Injection (unspecified) & $\begin{array}{l}\text { Morphine } \\
\text { preconditioning }\end{array}$ & $\begin{array}{c}\text { 2-DE + MALDI } \\
\text { TOF MS }\end{array}$ & 8 & Not reported \\
\hline $\begin{array}{l}\text { Abul-Husn et al, } \\
20111\end{array}$ & Sprague-Dawley rat & Striatum & PRE & $\begin{array}{l}\text { Escalating morphine: } \\
5-50 \mathrm{mg} / \mathrm{kg}\end{array}$ & $\begin{array}{l}2 \times / \text { day } \\
\text { for } 5 \text { days }\end{array}$ & IP & Dependence & $\begin{array}{l}\text { Succinic } \\
\text { anhydride }+ \\
\text { LC-MS/MS }\end{array}$ & 30 & $\begin{array}{l}\text { Vesicle trafficking, cytoskeleton } \\
\text { associated, cell adhesion signaling, } \\
\text { chaperone proteins }\end{array}$ \\
\hline Lin et al, 2011 & Wistar rat & Amygdala & Total homogenate & $\begin{array}{c}10 \mathrm{mg} / \mathrm{kg} \\
\text { (establishment) } \\
5 \mathrm{mg} / \mathrm{kg} \\
\text { (reinstatement) }\end{array}$ & - & $\mathbb{P}$ & $\begin{array}{l}\text { Conditioned place } \\
\text { preference }\end{array}$ & $\begin{array}{l}\text { 2-DE }+ \\
\text { MALDI- } \\
\text { TOF-TOF MS }\end{array}$ & $\begin{array}{l}80 \text { (variable by } \\
\text { phase of CPP) }\end{array}$ & $\begin{array}{l}\text { Metabolism, structure, cell signaling } \\
\text { pathway, ubiquitin-proteosome } \\
\text { pathway }\end{array}$ \\
\hline Wei et al, 2013 & Wistar rat & Hippocampus & Total homogenate & $\begin{array}{l}\text { Chronic escalating } \\
\text { morphine: } \\
\text { 10-50 mg/kg }\end{array}$ & $\begin{array}{l}3 \times / \text { day } \\
\text { for } 8 \text { days }\end{array}$ & SC & Dependence & $\begin{array}{l}\text { 2-DIGE + MALDI } \\
\text { TOF MS }\end{array}$ & $\begin{array}{l}\text { Phospha-tidyl- } \\
\text { ethanol-amine- } \\
\text { binding protein }\end{array}$ & Not reported \\
\hline Bu et al, 2012 & Rhesus monkey & $\begin{array}{l}\text { Nucleus } \\
\text { accumbens }\end{array}$ & Total homogenate & Escalating morphine & 90 Days & SC & Dependence & $\begin{array}{l}\text { 2-DE + } \\
\text { MALDI- } \\
\text { TOF-TOF }\end{array}$ & $28-33$ & Not reported \\
\hline Song et al, 2012 & $\begin{array}{l}\text { Sprague-Dawley } \\
\text { rat }\end{array}$ & $\begin{array}{l}\text { L4-L5 spinal } \\
\text { cord }\end{array}$ & Total homogenate & $10 \mu \mathrm{g}$ & $\begin{array}{l}2 \times / \text { day } \\
\text { for } 6 \text { days }\end{array}$ & IC & Tolerance & $\begin{array}{l}\text { 2-DE }+ \\
\text { MALDI- } \\
\text { TOF MS }\end{array}$ & $\begin{array}{l}13 \text { Proteins } \\
\text { identified }\end{array}$ & $\begin{array}{l}\text { Cytoske-letal, neurotrophic factors, } \\
\text { oxidative stress, ion metabolism, } \\
\text { cell signaling }\end{array}$ \\
\hline
\end{tabular}


proteins can be summarized by their membership in 6 broad functional categories: chaperones, cytoskeletal proteins, energy metabolism, local protein synthetic machinery, signal transduction, and synaptic transmission. Interestingly, this study observed significant upregulation of guanine nucleotide-binding protein $\beta$-subunits and isoforms of CaMKII during the acquisition phase of CPP. Equally interesting was the observation of a number of well-known presynaptic proteins that exhibited morphineregulated changes during CPP in this PSD fraction. These included syntaxin binding protein and synapsin II. Moreover, multiple spots were observed for synapsin II, suggesting the presence of differential states of posttranslational modifications during the reinstatement phase of CPP. Similar investigations in amygdala tissue homogenates following morphine-induced CPP (Lin et al, 2011) revealed 80 proteins that exhibited significant (at least 1.3-fold) changes, the majority of which were downregulated. As with other explorations of the morphinome, proteins that exhibited significant regulation in response to morphineinduced CPP were involved in structure, energy metabolism, cell signaling pathways, and the ubiquitin-proteasome pathway. The authors focused their explorations on mitogen-activated protein kinase 1 (MAPK1), which increased during CPP extinction and reinstatement, and glial fibrillary acidic protein (GFAP), which was significantly decreased during extinction. Among proteins contributing to cell structure, intriguing changes in septins, spectrins, and synapsin $1 \mathrm{~b}$, proteins linked to the structuring of synaptic contacts and to synaptic signaling, were also observed. As previously stated, a number of interesting proteins from the ubiquitin-proteasomal pathway were also identified, including ubiquitin carboxy-terminal hydrolase 1.1, proteasome subunits $\alpha$ types 3 and 6, $\beta$ types 4,3 , and 7 , and ubiquitin-specific protease 7 .

A pair of studies also investigated the effects of morphine and butorphanol on the expression of phosphotyrosyl proteins in the rat PFC (Kim et al, 2004, 2005), again utilizing the familiar combination of 2-DE and MALDI-TOF MS. Using miniosmotic pumps, rats received a continuous i.c.v. infusion of morphine or butorphanol for 3 days, and were killed $6 \mathrm{~h}$ after discontinuation of delivery of the drug. A combination of western blotting and neuroproteomic analyses was utilized in an effort to elucidate global alterations in the phospho-tyrosine proteome. When compared with saline-treated rats, animals that were morphine or butorphanol dependent exhibited significantly greater levels of phosphorylated proteins in the PFC. Moreover, important cytoskeletal proteins that have been implicated in the expression of synaptic plasticity, including isoforms of both actin and tubulin, were also significantly elevated in the dependent rat brains. Intriguingly, the guanine nucleotide-binding proteins $\mathrm{G}_{\alpha \mathrm{i}}$ and $\mathrm{G}_{\alpha_{\mathrm{o}}}$ were found to be expressed only in the PFC of morphine- and butorphanol-dependent rats. Taken together, the results of these studies suggest that structural changes in the neurons along with changes in axonal transport may significantly contribute to the phenomenology of dependence. More interesting still, the expression of $\mathrm{G}_{\alpha \mathrm{i}}$ and $\mathrm{G}_{\alpha_{\mathrm{o}}}$ only under conditions of morphine and butorphanol dependence suggests modulation of opioid receptor and/or other $\mathrm{G}$ proteincoupled receptor signal transduction during dependence.

Another interesting study of note with respect to exploration of morphinome via the use of 2-DE examined the effects of chronic escalating morphine exposure $(3 \times$ per day for 8 days delivered s.c.) resulting in dependence on the expression of phosphatidylethanolaminebinding protein (PEBP) in the hippocampus (Wei et al, 2013). PEBP was of interest as it is a precursor for the synthesis of hippocampal cholinergic neurostimulating peptide (HCNP), an abundance of which in turn enhances the synthesis of choline acetyltransferase (ChAT) as well as the development of cholinergic efferents from the medial septal nuclei directed toward the hippocampus. Utilizing 2-DE coupled with MALDI-TOF MS, it was observed that expression of PEBP was significantly upregulated in rats subjected to the chronic escalating morphine treatment. In addition, by examining levels of PEBP over the course of morphine dependence as well as withdrawal, a time course for PEBP expression emerged: levels of PEBP spiked upward during delivery of the chronic escalating morphine treatment, whereas they returned to normal levels $\sim 3$ days after withdrawal. However, as late as 28 days after the onset of withdrawal, levels of PEBP remained significantly upregulated.

An intriguing and unique study published recently by $\mathrm{Bu}$ et al (2012) utilized 2-DE coupled with MALDI-TOF/ TOF MS to explore changes in protein expression in NAc homogenates from Macaca mulatta in response to both morphine dependence and pharmacological interventions (clonidine and methadone) utilized in withdrawal intervention. Rhesus monkeys received 90 days of subcutaneous injections as part of a chronic escalating morphine treatment paradigm. Morphine injections were abruptly halted on day 91 of the experiment, and the morphinedependent animals received saline, clonidine $(0.02 \mathrm{mg} / \mathrm{kg}$ delivered i.g. $3 \times$ per day), or methadone $(6 \mathrm{mg} / \mathrm{kg}$ delivered i.g. daily) treatments for management of withdrawal symptoms for 7 days. During this period, signs of opiate withdrawal, including abdominal clutching, tremors, spasms, grimacing, flushing of the face, ptosis, dysphoria as revealed through facial expressions, and provoked screams, were assessed. At $24 \mathrm{~h}$ after the final treatment, the animals were killed, the NAc was rapidly dissected from each subject, homogenized, and subjected to 2-DE analysis coupled with MALDI-TOF/TOF MS. An average of 800 spots per gel were observed, and unique proteins that exhibited significant differences were successfully identified: 28 proteins in the morphine $v s$ saline condition, 33 proteins in the methadone $v s$ morphine condition, and 29 proteins in the clonidine vs morphine condition. These proteins represented six distinct functional groups: cytoskeletal proteins, metabolism and mitochondrial function, oxidative stress, protein synthesis and degradation, signal 
transduction, and synaptic transmission. Further analysis revealed that 14 of the unique proteins were common to all three conditions, and that 9 of these were downregulated whereas the remaining 5 were upregulated. Importantly, chaperone proteins such as Hsp70 were observed to be consistently upregulated across treatment conditions, whereas proteins involved in the ubiquitin-proteasome pathway (proteasome subunit $\alpha$ type-5), proteins involved in synaptic transmission ( $\alpha$-synuclein, $\beta$-synuclein), and proteins critically involved in signal transduction activity (calmodulin isoform 4) all exhibited significant downregulation across the three treatment conditions. As with other studies discussed, these findings again suggest that alterations in synaptic transmission, expression of heat shock proteins, and calcium signaling-related proteins may contribute to both the pathogenesis and the pharmacological management of opiate dependence. It is also necessary to note the relevance of this study for understanding molecular alterations resulting from morphine dependence and addiction in humans, as the findings by Bu et al (2012) represent the only neuroproteomic investigation of morphine-regulated alterations in a higher-order primate.

A series of additional studies have utilized differential isotopic labeling to investigate alterations in synaptic protein profiles in response to varying paradigms of morphine administration (Prokai et al, 2005; Moron et al, 2007). In the first of these studies, a 7-day paradigm of morphine exposure (continuously delivered via osmotic pump) was used to induce morphine dependence. Animals from the saline- and morphine-treatment groups were killed on day 8 and cortical synaptic fractions were then prepared, subjected to labeling with the isotopic reagent (isotopecoded affinity tag (ICAT)) coupled with LC-ESI-MS/MS (Prokai et al, 2005). The authors reported that 74 proteins were identified in total, of which 27 (10 increased and 17 decreased) exhibited significant morphine-dependent regulation. A number of proteins involved in cell adhesion (neural cell adhesion molecule, neurexin, and neurofascin), trafficking of synaptic vesicles (NSF), and endocytosis (clathrin, AP-2) exhibited significantly altered expression. There were also interesting downregulations in the abundance of postsynaptic proteins involved in G proteincoupled receptor signaling (guanine nucleotide-binding protein, $\beta$ ) and regulation of the postsynaptic membrane voltage potential $\left(\mathrm{Na}^{+} / \mathrm{K}^{+} /\right.$ATPase, $\left.\alpha / \beta\right)$. In addition, an intriguingly increased abundance of heat shock protein 60 , involved in oxidative stress, was also observed.

The overwhelming majority of proteomic studies seeking to explore morphine-regulated alterations in protein expression have utilized homogenates of the region of interest (Table 1). As discussed above, the major site of protein changes related to the induction of synaptic plasticity, which is thought to contribute to the lasting behavioral and physiological changes associated with addiction, are thought to occur at distinct subcellular compartments (such as synapses). More importantly, by examining only the homogenate of a region of interest, the relatively small yet significant changes in protein expression occurring at the synapse may be missed or diluted relative to the abundance of all the other proteins found in a given sample. It is for these reasons that many groups have focused on the application of subcellular fractionation coupled with quantitative proteomics approaches to explore morphineregulated changes in protein expression in fractions selectively enriched in either pre- or postsynaptic-related proteins.

\section{NEUROPROTEOMICS OF THE SYNAPSE}

Studies examining the effect of continued exposure to drugs of abuse have reported that persistent doses of morphine for 1 month result in a significant decrease in spine density as well as the overall complexity of dendritic arbors of medium spiny neurons (MSNs) in the shell of the nucleus accumbens (see Figure 1; Robinson and Kolb, 1999; Li et al, 2003; Robinson and Kolb, 1997, 2004; Russo et al, 2010) As these studies implied a role for local changes in the abundance of proteins at dendritic spines in response to chronic morphine exposure, efforts have been put toward isolating these subcellular compartments with the intent of identifying the changes in protein abundance at these locations. For this, differential density gradient centrifugation of the brain homogenates has been useful based on the idea that the purification of PSD fractions could be easily accomplished by isolating the detergent-insoluble components of synaptosomes (Cotman et al, 1974; Kennedy et al, 1983; Kelly et al, 1984; Stevens et al, 2003; Ramos-Ortolaza et al, 2010). A number of research groups have successfully applied the high-throughput methodologies of proteomics in seeking to identify the molecular and chemical components of the PSD (summarized below in Table 2).

Early proteomic investigations of the PSD used 2-DE coupled with various mass spectrometric methods in order to identify and characterize the molecular components of the PSD. The first such studies utilized 2-DE + MADLI-TOF (Walikonis et al, 2000), LC-ESI-MS/MS (Husi et al, 2000), and 2-DE + HPLC-MS/MS (Satoh et al, 2002) to identify 31, 71 , and 47 PSD-associated proteins, respectively. Although these studies identified only a small collection of proteins relative to the thousands of proteins now known to occupy the excitatory PSD (Bayes and Grant, 2009), they were among the first to identify additional PSD-associated proteins vital to postsynaptic functioning, including an array of cytoskeletal and scaffolding proteins, cell-adhesion molecules, and proteins modulating small G-protein signaling, adaptor proteins, glutamate receptors, and various signaling molecules (Husi et al, 2000; Walikonis et al, 2000; Satoh et al, 2002). Building upon these early results, more recent investigations have utilized proteomic techniques ranging from SDS-PAGE and 2-DE coupled with mass spectrometry (Jordan et al, 2004; Li et al, 2004; Peng et al, 2004; Collins et al, 2006; Dosemeci et al, 2006; Klemmer et al, 2009), to ICAT labeling or MudPIT (Li et al, 2004; 


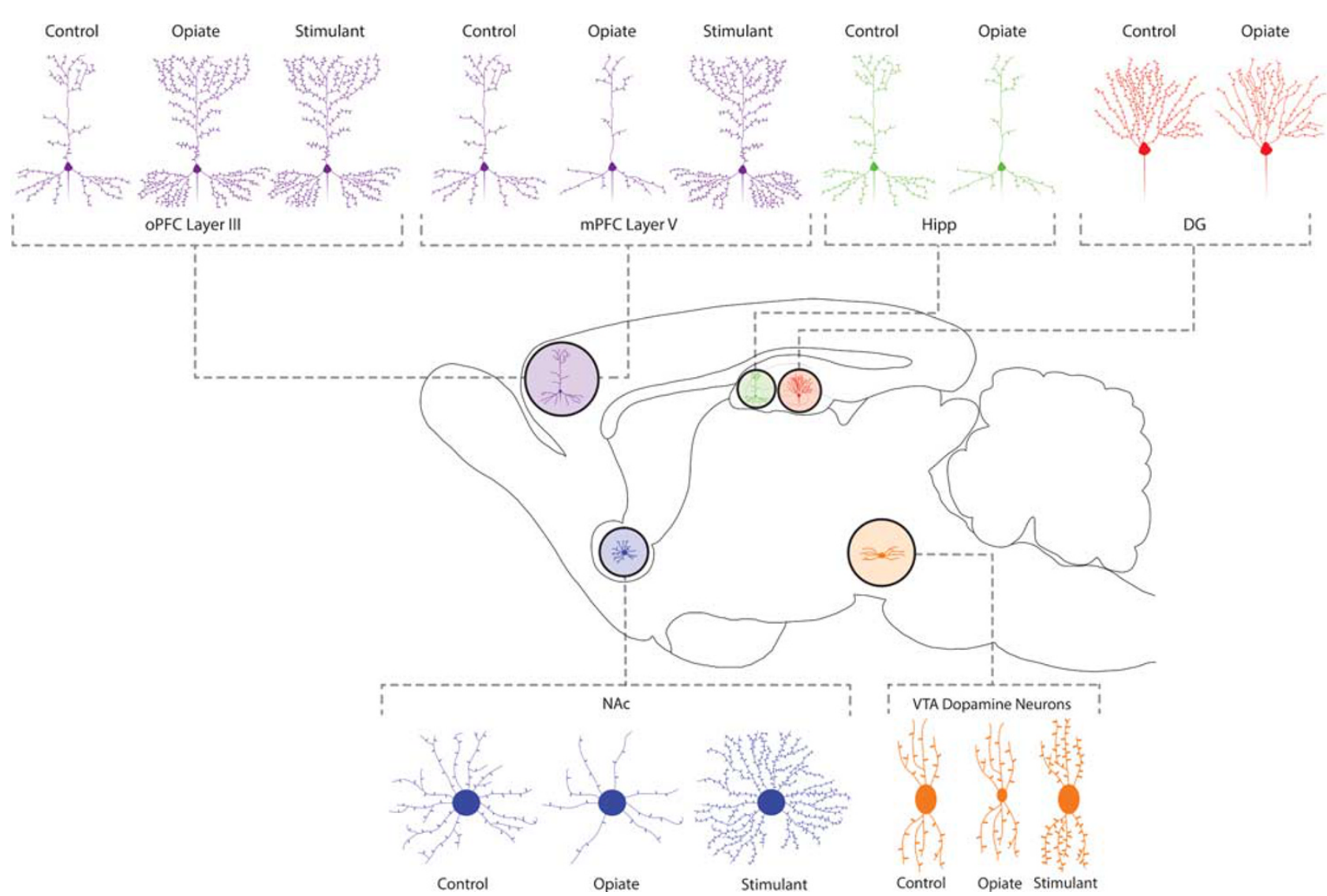

Figure 1. Primary cell types and anatomical regions involved in reward and addiction. Chronic administration of virtually any drug with a liability for abuse has been shown to result in neuroplasticity-related morphomolecular alterations throughout the reward circuitry of the nervous system. Persistent exposure to morphine for a period of 1 month resulted in significantly decreased spine density as well as overall dendritic arbor complexity. This effect was documented for medium spiny neurons (MSNs) in the shell of the nucleus accumbens (NAc), layer $V$ pyramidal neurons of the medial prefrontal cortex (mPFC), and hippocampus (HIPP), but not in the occipital prefrontal cortex (oPFC), dentate gyrus (DG), or ventral tegmental area (VTA).

TABLE 2 Previous Neuroproteomic Analyses of the Postsynaptic Density

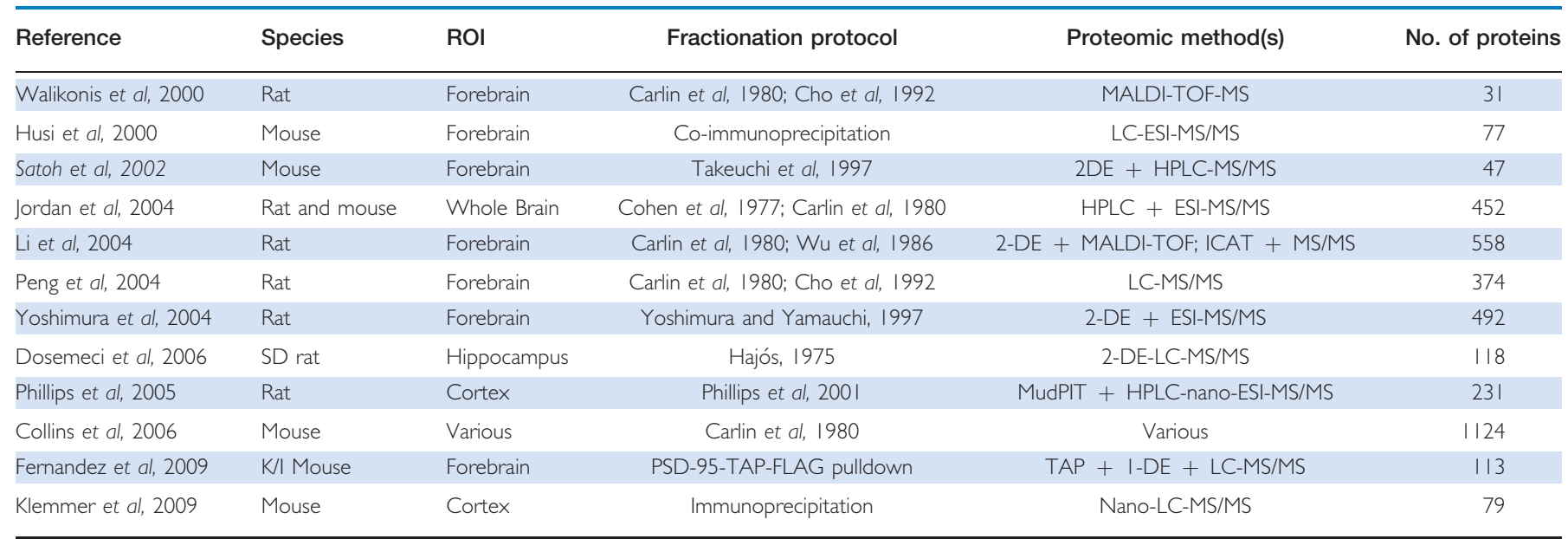

Yoshimura et al, 2004; Phillips et al, 2005; Schrimpf et al, 2005; Moron et al, 2007), and even tandem affinity purification (TAP) tagged-PSD-95 knock-in mice coupled with 1-DE and LC-MS/MS analysis (Fernandez et al, 2009) to identify thousands of proteins that are associated with the structure and function of the excitatory PSD (Collins et al, 2006; Fernandez et al, 2009; summarized in Table 2). Although the importance of these studies in elucidating the molecular and chemical components of the excitatory PSD cannot be overstated, only recently have the powerful tools 
of proteomics been utilized to explore alterations in the proteomic profile of the PSD following exposure to drugs of abuse, including morphine and other opiates.

\section{NEUROPROTEOMICS OF THE MORPHINE-DEPENDENT SYNAPSE}

The first study to examine alterations in the protein profile of mouse hippocampal PSD proteins in response to a 2-day escalating morphine treatment paradigm employed ICAT labeling (Moron et al, 2007). A total of 102 proteins involved in trafficking, signaling, receptors/channels or carriers, cell adhesion, cytoskeletal, regulatory, and metabolic processes were documented. Although many of these proteins have established roles in learning, memory, and synaptic plasticity, the expression of clathrin exhibited the greatest degree of elevated expression. In probing further with the convergent methodologies of western blotting and co-immunoprecipitation, it was demonstrated that the increased clathrin expression was PSD fraction specific. Moreover, additional endocytic proteins, including dynamin and AP-2, also exhibited enhanced expression in the PSD fraction only in response to morphine. Taken together, these data suggest a specific recruitment of clathrin to the PSD, as well as a significant contribution of endocytic machinery to the emergence of morphine-regulated changes in protein expression at the synapse. Importantly, the relevance of this finding to synaptic functioning was also examined via an exploration of the association between clathrin and the GluR1 subunit of the AMPA receptor. Subsequent to morphine exposure, the interactions between these two proteins were found to be significantly decreased. When taken together, these findings suggest that exposure to morphine ultimately reduces endocytosis of AMPA receptors, in turn resulting in a redistribution of molecules involved in endocytosis, including clathrin, to the postsynapse.

With an intent of identifying changes in the presynaptic proteins in response to morphine treatment, Abul-Husn et al (2011) used a combination of subcellular fractionation (see Figure 2) with differential isotopic labeling to identify morphine-regulated presynaptic proteins. For this, succinic anhydride was used as a label and changes in striatal presynaptic proteins in response to a chronic escalating dose of morphine treatment was examined. This analysis revealed 30 proteins to be significantly altered and these included proteins involved in vesicle trafficking, signaling, and cell adhesion. In order to identify proteins that eluded mass spectrometric identification, the systems biology approach was used (this is described in detail in the section 'Systems biology and the construction of biological networks'). By integrating the list of proteins into a network representing potential morphine-regulated presynaptic signaling complexes and analyzing this network using graph theory-based methods (Abul-Husn and Devi, 2006; AbulHusn et al, 2009); clusters of densely connected and
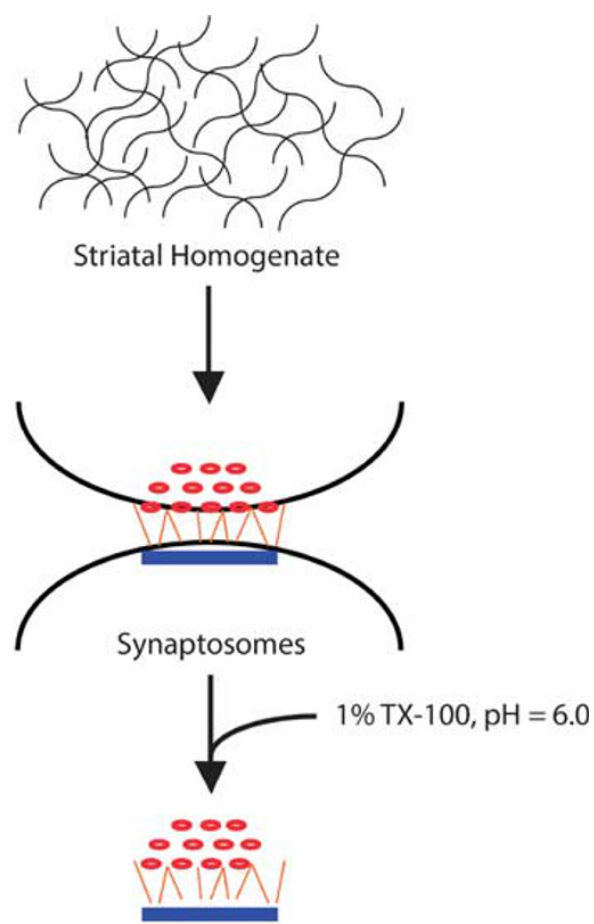

Synaptic Junctions

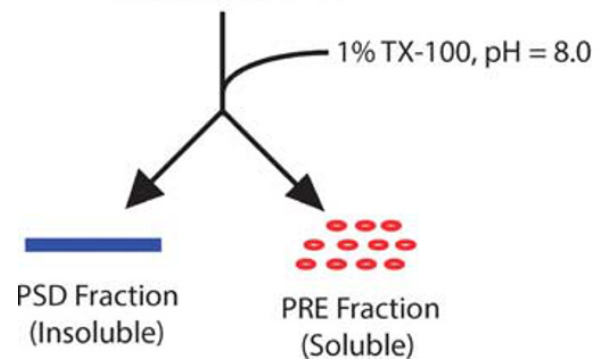

Figure 2. Schematic diagram of the subcellular fractionation protocol. A schematic of the subcellular fractionation protocol used with rat striatal tissue samples to separate presynaptic, soluble fractions from insoluble postsynaptic fractions (adapted from Phillips et al, 2001).

functionally related proteins were identified (Abul-Husn et al, 2011). This allowed the prediction of novel proteins that are likely to be regulated by morphine, several of which were verified biochemically. Of greatest interest was a cluster involving molecular chaperones that were downregulated by morphine. These molecular chaperones are likely to be involved in mediating morphine-induced alterations in neurotransmitter release and synaptic plasticity events. Thus, these studies provide candidates for subsequent functional studies to determine the specific role of presynaptic proteins in morphine-related behavioral and physiological effects.

At present, there are two significant limitations to the data provided by proteomic experiments regarding the altered expression of proteins in response to exposure to morphine. For instance, although morphine-regulated alterations in the aforementioned broad families of proteins has been consistently demonstrated via previous proteomic studies, the molecular mechanisms underlying these 
changes have yet to be conclusively elucidated. In trying to address this question, the second limitation to current proteomics data sets becomes readily apparent: of the proteomic investigations that explored morphine dependence and addiction, the overwhelming majority revealed nothing more than a lengthy list of proteins that were detected among the samples submitted for analysis. A major challenge, therefore, is to utilize the ever-evolving tools of systems biology and bioinformatics in an effort to organize and make sense of the large volumes of proteomic data being generated.

\section{SYSTEMS BIOLOGY AND THE CONSTRUCTION OF BIOLOGICAL NETWORKS}

\section{Systems Biology and Protein-Protein Interaction Databases}

Recent advances in the biological sciences, including the advent of modern high-throughput methodologies such as those used in proteomic experiments, have made it possible to generate extensive lists of proteins found in a given region of interest or a particular subcellular compartment. However, what has been less clear is how to understand and interpret these massive data sets with respect to their biological and functional significance. The emerging discipline of systems biology, which seeks to understand biological complexity through the lens of mathematical and computational principles, has started to make the analysis of such massive data sets possible. By combining the approaches of systems biology with graph theory, data sets consisting of genes, mRNA, proteins, and other small molecules can be organized into visualized network graphs wherein the items from the experimentally derived list are assembled into connectivity maps based upon the known interactions that occur between them (Abul-Husn et al, 2009; Jenkins and Ma'ayan, 2013). In general, there are two ways in which a protein-protein interaction (PPI) network can be generated: through the use of literature mining or automatically through the use of specialized, purposedriven software tools. In the former method, the interested researcher has to manually review the relevant research literature regarding proteins of interest and known interacting proteins. This approach to PPI construction has been successfully used to construct a network representation of the hippocampal CA1 neuron (Ma'ayan et al, 2005), and also in an exploration of the morphine-dependent presynaptic terminal in the striatum (Abul-Husn et al, 2011). Figure 3 provides an example of such a network of a morphine-dependent postsynaptic terminal in the striatum.

\section{Graph Theory and the Analysis of Biological Networks}

In mathematical language, all of the aforementioned networks can actually be thought of as graphs, wherein proteins, genes, or small molecules of interest are represented by nodes, whereas the interactions between them are represented as lines known as edges (in undirected networks) or arcs (in directed networks) (Berger et al, 2007; Taylor and Wrana, 2012). It is important to note that most PPI and gene networks are plotted as undirected graphs, wherein the edge between two nodes simply indicates an interaction without an implication of direction. Conversely, networks describing phosphorylation events or metabolic processes are said to be directional in that the indicated interaction occurring between two nodes has a well-defined directionality (Barabási and Oltvai, 2004). There are a number of significant advantages that are gained as a consequence of converting molecular signaling pathways or PPIs into a plotted graph, the most significant of which is the ability to analyze the network through the application of graph theory.

For any network graph, there are a number of critical features that describe the architecture of the network while also detailing significant information regarding the presence of network modules and their functions, the functions of individual components of the network, as well as the interactions that occur between network components and network modules. Among these are the topological features of the network graph, the most common of which include degree, distance, diameter, and clustering coefficient (Taylor and Wrana, 2012; Albert and Barabási, 2002). Degree, also known as connectivity, simply describes the number of links that any one node makes to other nodes in the network. With respect to degree, larger values indicate more densely connected nodes, and more densely connected nodes are more likely to be critically involved in the functions and activity of the network being analyzed. The second topological parameter, distance, indicates the shortest path length that occurs between any two nodes in the network. Diameter refers to the maximum distance occurring between any two nodes in a given network. Finally, the clustering coefficient of a network node reports a ratio of the number of links that occur between a node and its local network neighborhood relative to the maximum number of links that are possible between these nodes (Taylor and Wrana, 2012; Barabási and Oltvai, 2004; Albert and Barabási, 2002). With an understanding of the topological features of a network in mind, when conducting a network analysis it is also important to consider the global features of a network graph, including the architecture of the graph itself.

Primarily as a consequence of the growing popularity of this approach for the organization and investigation of large data sets generated via high-throughput methods, a multitude of bioinformatics-driven networks have been generated to date. The abundance of these data has ultimately enabled the identification of several properties that appear to be inherent to most, if not all, biological networks (Albert and Barabási, 2002). Initially, it was thought that networks describing real-world phenomena could be described using a random network model, where it is assumed that a fixed 


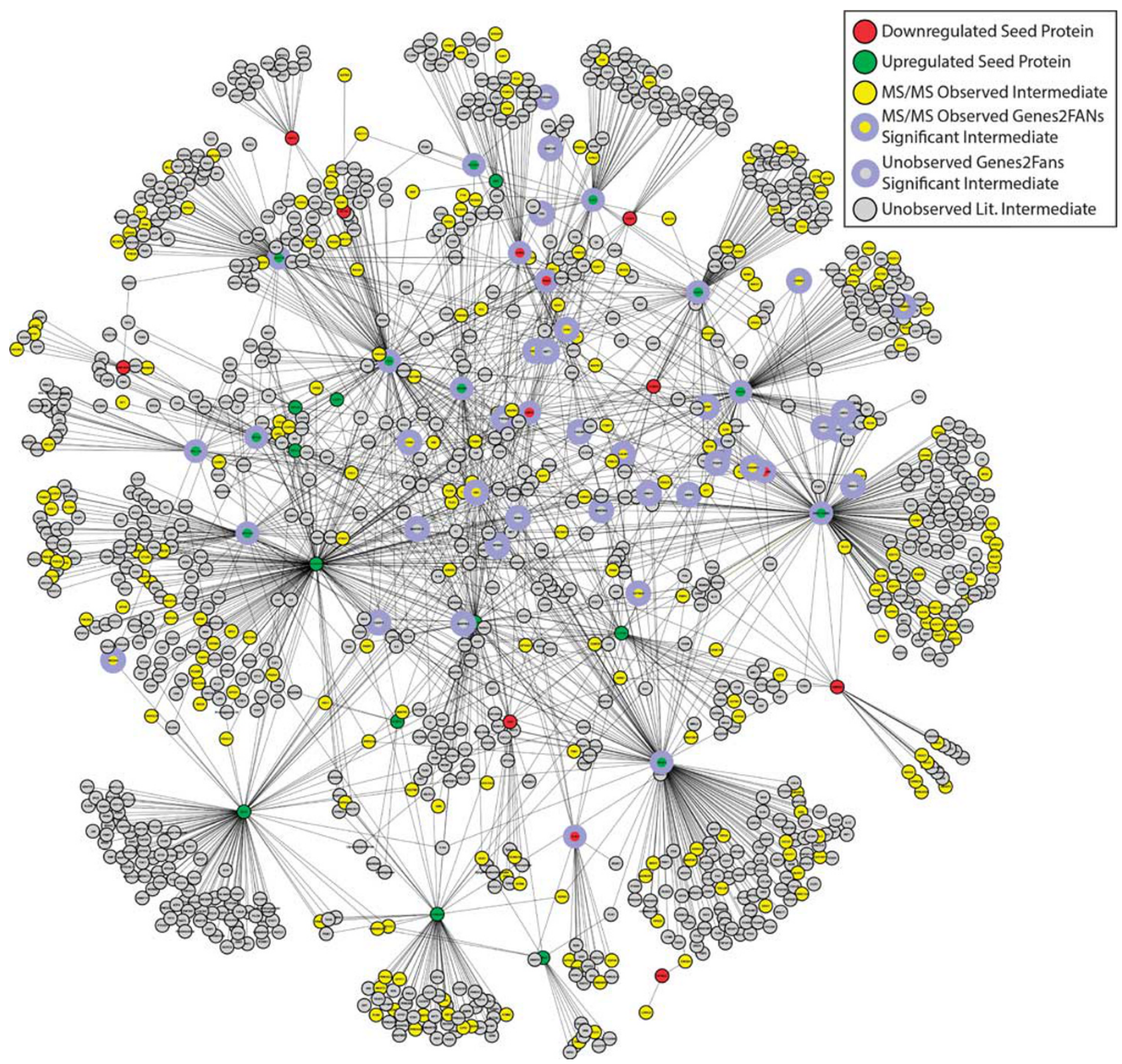

Figure 3. Protein-protein interaction (PPI) network. A PPI network generated by conducting literature searches for proteins that interact with the list of morphine-regulated proteins identified in a previous investigation. In total, this network consists of 1176 nodes that are connected through 1751 edges. Upregulated and downregulated seed proteins are highlighted in green and red respectively. Yellow nodes indicate proteins that were identified as seed list interactors and observed by MS/MS analysis. Nodes highlighted in gray indicate literature-identified seed list interactors that were not observed by MS/MS analysis. Finally, nodes circled in purple indicate proteins identified as being highly significant intermediates by the previous Genes2Fans analysis.

number of network nodes are connected to each other in a completely random manner (Barabasi and Albert, 1999; Barabási and Oltvai, 2004; Albert and Barabási, 2002). However, currently it is well established that most, if not all, biological and real-world networks actually exist in a scalefree format (Barabási and Oltvai, 2004; Albert and Barabási, 2002). The characteristic feature of scale-free networks, which include biological, social, and technological networks, is that they can be described by a power-law degree distribution. Stated mathematically, the power-law distribution reports the probability that the distribution of the node degree, $k$, for any randomly selected node such that $P(k)$ $\sim k^{-\gamma}$, where $\gamma$ is the degree exponent. Ultimately, the power-law distribution of the node degree means that scalefree networks are nonuniform in nature. Importantly, although most network nodes in a scale-free network will only have one or a few links, such networks will have just a few nodes that serve as network hubs in that they are very densely connected to the rest of the network and hold it together (Barabási and Oltvai, 2004; Albert and Barabási, 2002). As a consequence of this pattern of organization, scale-free networks, tend to be resilient to perturbation and 
disruption: random disruption or deletion of a node (a protein or gene, in the case of biological networks) is unlikely to significantly disrupt the functioning of the network, though the disruption of a hub protein will likely result in more dramatic changes in network functioning and output.

There is an additionally important feature that is present in network graphs that describe biological and other realworld networks, namely that they possess a small-world property. The presence of the small-world property in a given network graph is indicated when any two nodes can be connected using a path length of only one or a few links (Watts and Strogatz, 1998). Although the small-world property can be observed in both random and scale-free networks, recent work has demonstrated that the small world of scale-free networks can actually be thought of as being 'ultra-small' in nature (Jeong et al, 2000; Wagner and Fell, 2001). There are several implications of this ultra-small world property with respect to biological networks. It indicates that, not only are these networks highly interconnected, but changes in a single protein may have the potential to easily and very rapidly affect many other proteins (Watts and Strogatz, 1998). These properties were first demonstrated with metabolic pathways, where it was shown that most metabolites could be linked with path lengths of just three to four reactions (Jeong et al, 2000; Wagner and Fell, 2001). Similar findings have been documented for networks identified within the postsynaptic proteome, specifically regarding signaling cascades associated with NMDA receptors (Pocklington et al, 2006; Grant, 2003). In these studies, network graphs of NMDA receptor complexes and the proteome of the postsynapse in general revealed network diameters of 3.26 and 3.82 respectively. These findings suggest that the subcellular compartment of the postsynapse can best be described as being a 'small world', wherein on average each protein is less than four connections away from any other protein (Pocklington $\mathrm{et} \mathrm{al}$, 2006; Grant, 2003). Taken together, the small-world and scale-free nature of biological networks generally indicates that their architecture is quite robust with respect to their signaling properties. In addition, the combination of these properties also indicates that there is a substantial degree of cross-talk between various signaling pathways and network components within the postsynaptome (postsynaptome refers to the set of proteins at the postsynaptic density).

Biological network graphs are also characterized by the presence of modules, defined as groups of physically or functionally interconnected nodes that are united in so far as they achieve a common goal through collaborative function (Barabási and Oltvai, 2004). By the start of the twenty-first century, it became apparent that most cellular functions are carried out by groups of proteins or small molecules that exist within such functional modules (Hartwell et al, 1999). At least two types of functional modules have been identified in biological network graphs: network motifs and subgraphs. Network motifs are defined as patterns of interconnections that are observed within a network more frequently than would be expected by chance alone (Milo et al, 2002). With respect to central nervous system-related network graphs, motifs have been identified in a number of networks, including that of the CA1 hippocampal neuron (Ma'ayan et al, 2005).

As previously mentioned, an additional example of a module found in biological networks is the subgraph. Subgraphs, which can also be thought of as clusters, are highly interacting, functionally related nodes that are more densely connected to each other than they are to the rest of the network at large. In comparison with random networks, which exhibit few if any clusters, scale-free networks have been shown to be significantly enriched in clusters (Spirin and Mirny, 2003). Importantly, the presence of clusters in scale-free networks supports the suppositions made regarding their modular architecture (Hartwell et al, 1999). In general, two main types of subgraphs have been observed in network graphs, dynamic functional modules and protein complexes (Spirin and Mirny, 2003). Dynamic functional modules represent a small group of proteins that regulate or perform some specific cellular function through their interactions. Proteins involved in dynamic functional modules need not interact at the same time and same place. An example of such a dynamic functional module would be intracellular signaling cascades, where a series of different proteins with differing subcellular localizations work together to achieve a common final goal. Protein complexes, on the other hand, are groups of proteins that must interact together at the same time and same place in order to achieve the desired goal (Spirin and Mirny, 2003). The identification of clusters within a network is typically accomplished using purpose-designed software, and there are many different algorithms that are frequently utilized to identify clusters in PPI networks (Brun et al, 2004).

\section{Generation of Testable Hypotheses from Network Graphs}

As previously discussed, plotting complex cellular processes as a network graph allows for the application of graph theory and a variety of mathematical algorithms to better understand the topology and functions carried out by these networks, the global architecture of such networks, and most important of all, predict the presence of additional nodes or structural elements of the network as well as dynamic properties of the network. By utilizing predictive analytic tools, networks that have been generated can ultimately result in the validation of interactions, identification of novel relationships within the network, and also novel hypotheses that can be tested at the bench (Figure 4).

There are a number of methods through which testable hypotheses can be generated using network graphs; however, the identification of physical interactions between proteins is considered to be the method of choice when attempting to elucidate novel or unknown protein functions (Okada et al, 2005; Sharan et al, 2007; Samanta and Liang, 2003). This task is made simpler when carried out in the context of analyzing a graph theory-inspired PPI network 

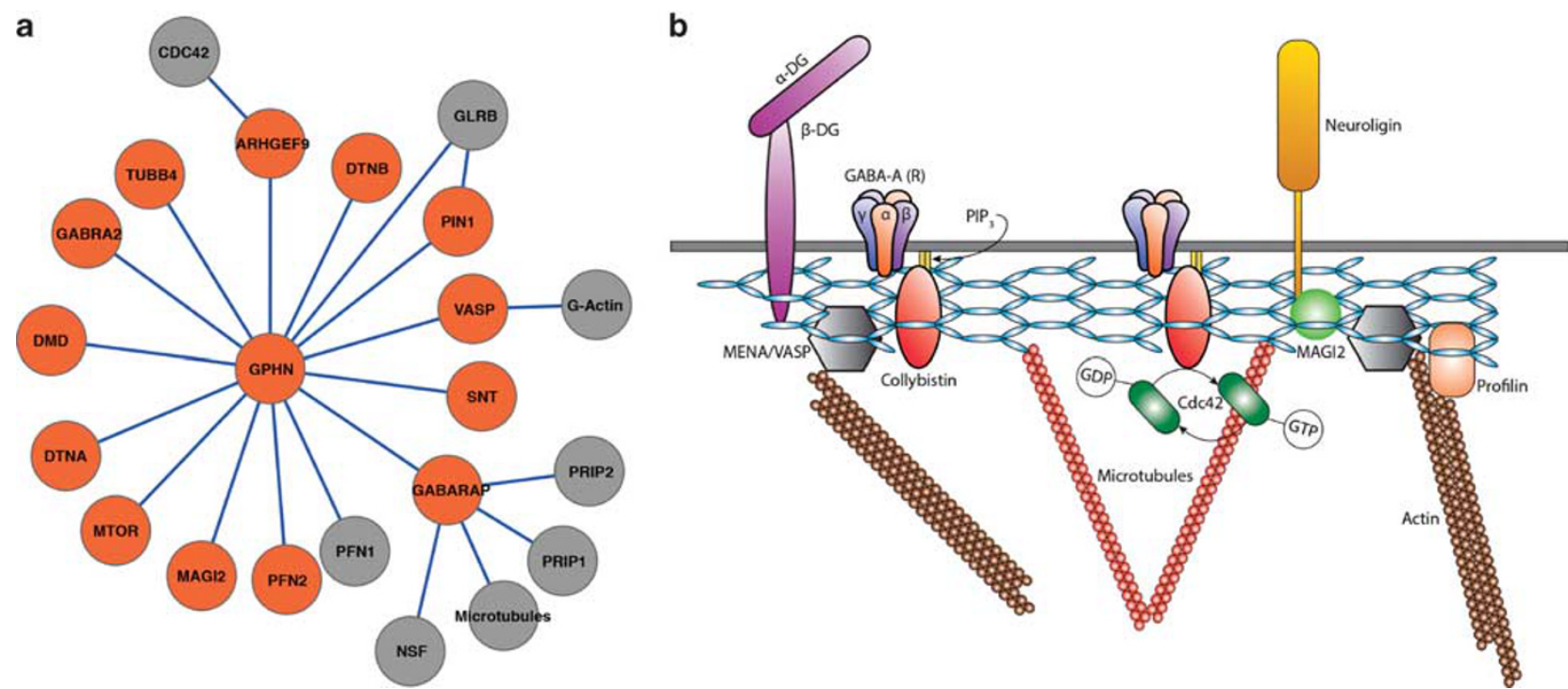

Figure 4. Molecular components of GABAergic synapses identified by MS/MS analysis. A substantial number of proteins typically associated with GABAergic synapses were identified in samples subjected to MS/MS analysis during the present investigation. Although none exhibited significantly altered expression, as revealed by MS/MS analysis, their presence suggests that the PSD isolates used for the present investigation included materials from other postsynaptic regions beyond the excitatory PSD.

based upon the notion that proteins that are closer to each other within the span of the network are more likely to have comparable functions (Sharan et al, 2007). Taken together, in generating interaction networks from protein lists derived via high-throughput experiments, it then becomes possible to generate functional predictions regarding uncharacterized or missing network proteins based on the interactions with other proteins in the network. There are multiple methods by which functionally associated proteins from a network can be extracted. In the first approach, functionally associated proteins are deduced by focusing on pairs of proteins possessing large numbers of interacting partners in common. Alternatively, given that various domains of a given protein regulate the interactions in which it participates, others have focused on identifying proteins that have both common interacting partners in addition to common domains (Okada et al, 2005).

Another method whereby novel functions for individual proteins can be elucidated is to focus on proteins that are united by their membership in specific protein clusters wherein all proteins have similar biological functions, a so-called module-assisted approach (Sharan et al, 2007). As previously discussed, it has been demonstrated that there is an increased likelihood that proteins that share a cluster will have similar biological functions. There are a number of predictions that can be made using this approach including the identification of previously unknown protein complexes, functional modules, novel proteins participating in known protein complexes, as well as the participation of novel proteins in known complexes (Spirin and Mirny, 2003). This latter approach was previously shown to be effective by Pocklington et al (2006) while investigating the NMDA receptor complex. In this particular study, five large clusters, as well as several smaller clusters, correlated with specific synaptic functions and behavioral phenotypes were identified (Pocklington et al, 2006).

Although graph theory-inspired methods have been growing in popularity and sophistication, relatively few studies exploring drug addiction have utilized these approaches. The successful application of these methods was recently demonstrated by Abul-Husn et al (2011) while investigating morphine-regulated alterations in the protein profile of striatal presynaptic fractions.

As previously mentioned, Abul-Husn et al (2011) sought to understand morphine-regulated presynaptic PPI within the striatum using an integrated proteomic approach. To start, subcellular fractions selectively enriched in presynaptic proteins were subjected to quantitative MS/MS analysis using isotopic labeling methods to both identify and quantify presynaptic proteins present in samples from saline-control and morphine-dependent Sprague-Dawley rats. The MS/MS analysis resulted in the identification of a total of 175 proteins, of which 143 were quantified. Among the quantifiable proteins, 30 exhibited significant regulation in response to morphine dependence. These 30 morphineregulated proteins were used as a seed list for the generation of a presynaptic PPI using a specialized software suite known as Genes2Networks: a web tool that integrates expertly curated information from existing large-scale, high-quality databases to connect seed lists of proteins using previously characterized PPIs (Berger et al, 2007). In utilizing this approach, these investigators sought to identify novel intermediate proteins that could represent potential therapeutic targets of interest for the treatment of morphine dependence and addiction. A graph theoryinspired analysis of the resultant network identified a series 
of significantly interconnected clusters of nodes, one of which included two significantly downregulated proteins: cysteine-string protein (CSP) and the heat shock protein HSP70. Intriguingly, HSP90, a heat shock protein that commonly interacts with CSP and HSP70, was observed to be significantly upregulated in response to morphine dependence, and was therefore selected as a target of interest. Inhibition of HSP90 through administration of a selective inhibitor, geldanamycin, was then shown to decrease the physical signs of naloxone-precipitated withdrawal from morphine dependence (Abul-Husn et al, 2011). Together, these results demonstrate that bioinformatic approaches coupled with systems biology and the generation of interaction networks is useful not only for organizing large data sets derived from high-throughput experiments, but also for the generation of novel hypotheses that can lead to the identification of new targets for therapeutic intervention in disease processes including addiction. Although this study represents the only known application of integrated proteomic approaches and network analyses to explore morphine regulated changes in a presynaptic fraction, it is important to note that, to date, similar analyses have yet to be performed in striatal postsynaptic density-related fractions. As outlined in previous sections, this research question is of critical importance given that the PSD represents a major site of synaptic plasticity in addition to morphine-regulated morphomolecular synaptic alterations in the central nervous system.

\section{CONCLUSIONS AND PERSPECTIVES}

As outlined above, a range of experimental evidence utilizing convergent methodologies has demonstrated the capacity of morphine and other opiates to induce significant and persistent alterations in synaptic transmission (both pre- and postsynaptically), dendritic morphology, and protein expression across a wide range of anatomical and neuroanatomical regions. Although the role of the striatum in addiction has been well studied, alterations in the neuroproteomic profile of postsynaptic density proteins in this region that are regulated by morphine dependence have not. In addition, examination of how morphine modulates the neuroproteomic profile of individual cell populations in the striatum (eg, D1 and D2 neurons in the striatum) as well as in different cellular compartments (eg, cytosolic vs nuclear) would be of interest in understanding how tolerance and addiction to this drug develops as well as in the identification of potential targets for the treatment of morphine dependence and addiction.

As is readily apparent upon a review of Tables 1 and 2, the interpretation and comparison of proteomic findings regarding morphine-regulated alterations in protein expression is made difficult as a consequence of a number of factors, the most significant of which is variability among paradigms of morphine administration used in each of the various studies. Indeed, for each of the studies discussed above, there is tremendous variation with respect to the dose of morphine used, the frequency, rate and route of administration selected, as well as the duration of exposure to morphine. Further complicating this issue is a lack of consensus regarding the appropriate latency between the termination of morphine administration and the killing of the animal subjects. Following the administration of a prolonged morphine treatment protocol, all of the aforementioned factors may impact the rate at which animals participating in the study convert from a state of morphine dependence to one of morphine withdrawal (Farrell, 1994). Beyond issues surrounding the administration of morphine, the direct comparison of the proteomic data is further complicated by the fact that these studies examined a wide range of anatomical regions, both within and beyond the central nervous system. Moreover, most of these studies investigated alterations in protein expression regulated by morphine using total homogenates of the region or sample of interest. Others, meanwhile, used subcellular fractionation techniques to generate samples enriched in presynaptic or PSD-related proteins, which were then subjected to proteomic analysis. Although the former approach (homogenate samples) provides excellent data regarding global changes in alterations in protein expression profiles in response to morphine administration, it likely fails to report significant morphine-induced proteomic changes that occur at the level of the synapse; synaptic proteins exist in relatively low abundance to begin with, and would be extremely diluted in a total homogenate sample. As such, subcellular fractionation, while generating a smaller sample for analysis, also permits the generation of a sample that is selectively enriched in proteins of interest to the study of morphine-regulated proteomic alterations accompanying synaptic plasticity. A final concern involves the use of a wide variety of proteomic methods for the characterization of samples. Not only do the many documented approaches label enzymatically digested peptides in different ways (ex ICAT vs iTRAQ labeling, discussed above), there is evidence that the number of proteins detected and identified can vary by as much as $200 \%$ (as is the case when iTRAQ and labelfree methods were compared head to head using identical samples (Patel et al, 2009)). Clearly, although these studies have advanced our understanding of molecular alterations that occur in response to exposure to morphine, the field of proteomics would benefit from greater standardization of labeling techniques, methods, and morphine administration protocols for the induction of tolerance and physical dependence. Such standardization would permit greater comparison of results across studies and, as such, facilitate a greater understanding of morphine-regulated changes in protein expression.

Although the aforementioned limitations regarding the comparison of proteomic results from multiple studies must always be considered, it is intriguing and important to note that, despite the variety of methods, species, and protocols employed thus far, a number of consistent alterations in protein expression have been documented in response to 
morphine exposure. One of the most consistent findings to date has been the significant regulation of proteins involved in the ubiquitin-proteasomal pathway in response to morphine exposure (Li et al, 2006, 2009; Lin et al, 2011; $\mathrm{Bu}$ et al, 2012). Ubiquitination is a common form of posttranslational modification, best known for its role in tagging proteins for degradation via the ubiquitinproteasome system (UPS) (Wang et al, 2013). This process can be broken down into two broad steps. The first involves conjugation of ubiquitin to molecules or proteins targeted for degradation through the sequential activity of enzymes known as E1, E2, and E3 ubiquitin ligases, with the E3 ubiquitin ligase ultimately determining the specific identity of the target to be ubiquitinylated. Following the covalent attachment of ubiquitin to the selected target molecule, ubiquitin-tagged proteins are then subjected to degradation by the proteasome. The majority of proteins, including those that are fully functional but no longer needed by the cell, will be subjected to degradation through this system (Wang et al, 2013). The UPS is known to contribute significantly to maintenance and regulation of physiological processes at the synapse, including LTP (Hegde et al, 1993) and LTD (Fioravante et al, 2008). Given the diversity of functions of the UPS in both synaptic plasticity and disease, it is intriguing that the final unified group of proteins that exhibited significant regulation in response to morphine were those involved in targeted protein degradation and the UPS. It is important to note, however, that the observation of significantly altered UPS-related proteins is among the most common findings from previous proteomic investigations of the morphinome (Kim et al, 2005; Li et al, 2006, 2009Lin et al, 2011; Bu et al, 2012). Interestingly, no two studies reported significantly altered expression of the same UPS proteins. Although these various results may at first seem in conflict, here again the comparison of results across proteomic studies is made difficult by the variety of species used, the different regions and subcellular regions analyzed, and significant variability across morphine treatment paradigms that were applied (Cheng et al, 2006).

In addition, a number of studies also observed consistent and significant morphine-regulated alterations in the expression of chaperone proteins, specifically heat shock proteins including Hsp60 and Hsp70 (Prokai et al, 2005; Shui et al, 2007; Yang et al, 2007; Suder et al, 2009; Bu et al, 2012). Heat shock proteins such as HSP70 and HSP90 often serve as molecular chaperones, and both iTRAQ + MS/MS analysis and western Blotting analyses have confirmed the presence of significantly elevated levels of HSP70 in the striatal PSD fraction following the induction of morphine dependence. Intriguingly, significantly altered expression of heat shock and heat shock-related proteins represents one of the most common observations from neuroproteomic investigations of the morphinome. However, findings regarding the up- or downregulation of heat shock and related proteins following morphine exposure have been variable. While investigating postsynaptic fractions from the PFC following morphine-induced CPP, downregulation of heat shock protein transcription factor 2 binding protein was observed, although only during the reinstatement phase of CPP (Yang et al, 2007; Bu et al, 2012). Conversely, Li et al (2009) documented an increase in HSP72 in dorsal root ganglion cells subsequent to a 4-day escalating dependence paradigm, whereas the abundance of several heat shock proteins (HSC71, HSP1B, and HSP86) was upregulated in mouse hippocampal PSD fractions after short-term morphine treatment (Moron et al, 2007). Furthermore, a 7-day chronic morphine administration resulted in significantly elevated levels of HSP60 relative to saline controls (Prokai et al, 2005). Yet, HSP70 was found to be significantly downregulated in the primate NAc during the development of morphine dependence as well as during withdrawal while treated with either methadone or clonidine ( $\mathrm{Bu}$ et al, 2012), and in the spinal cord of rats after repeated intrathecal morphine injections (Shui et al, 2007).

In documenting alterations in the proteomic profile of the striatal presynapse as a consequence of morphine dependence, Abul-Husn et al (2011) observed a significant downregulation of HSC70, a member of the HSP70 family of proteins. Inspired by this finding, as well as predictions from a graph theory-inspired network, the authors then investigated the abundance of two proteins known to complex with HSC70, CSP and HSP90. Although CSP was significantly decreased at striatal presynapses, HSP90 was significantly upregulated, suggesting that disruption of the HSC70-CSP-HSP90 complex resulted in a redistribution of HSC70 and CSP away from the synapse, leaving HSP90 behind (Abul-Husn et al, 2011). These studies underscore the utility of a combination of subcellular fractionation, differential isotopic labeling coupled to mass spectrometry with systems biology approach for the prediction and identification of selective protein abundance changes at the synapse. Hence, in order to better understand the functional interactions that occur among the identified proteins, and those that exhibit significant morphine-regulated changes in expression, the data from the integrated quantitative proteomic approach should be coupled with systems biology to generate a functional interaction network. The purpose of this functional interaction network will facilitate prediction of protein complexes and signaling pathways that unite the various regulated proteins while simultaneously identifying novel interacting proteins that could represent potential therapeutic targets for the treatment of CNS pathologies including morphine dependence and addiction.

Together, the proteins that exhibit significantly altered expression in response to morphine dependence are likely to be critically involved in the development of tolerance and addiction to opiates. Modulation of these proteins may ultimately contribute to the development of better opiate therapeutic medications characterized by minimal tolerance to their analgesic effects and/or a significantly reduced risk of developing dependence and addiction in response to their use in the clinical setting. 


\section{FUNDING AND DISCLOSURE}

The authors declare no conflict of interest.

\section{ACKNOWLEDGEMENTS}

LAD is supported by NIH grants DA008863 and DA019521. We thank Dr Ivone Gomes for critical reading of the manuscript.

\section{REFERENCES}

Abul-Husn NS, Annangudi SP, Ma'ayan A, Ramos-Ortolaza DL, Stockton SD Jr, Gomes I et al. (2011). Chronic morphine alters the presynaptic protein profile: identification of novel molecular targets using proteomics and network analysis. PLOS One 6: e25535 This paper reports the characterization of the morphine-regulated presynaptic protein network using a combination of subcellular fractionation, quantitative peptidomics and graph theoryinspired network analysis

Abul-Husn NS, Bushlin I, Morón JA, Jenkins SL, Dolios G, Wang R et al. (2009). Systems approach to explore components and interactions in the presynapse. Proteomics 9: 3303-3315. This paper describes the use of a combination of techniques (proteomics, data integration, and computational analyses) to obtain comprehensive understanding of functional components, especially low-abundance entities and/or interactions at the presynaptic terminal.

Abul-Husn NS, Devi LA (2006). Neuroproteomics of the synapse and drug addiction. J Pharmacol Exp Ther 318: 461-468.

Abul-Husn NS, Sutak M, Milne B, Jhamandas K (2007). Augmentation of spinal morphine analgesia and inhibition of tolerance by low doses of mu- and deltaopioid receptor antagonists. Br J Pharmacol 151: 877-887.

Al-Hasani R, Bruchas MR (2011). Molecular mechanisms of opioid receptordependent signaling and behavior. Anesthesiology 115: 1363-1381.

Albert R, Barabási AL (2002). Statistical mechanics of complex networks. Rev Mod Phys 74: 47-97.

Association AP (2000). Diagnostic and Statistical Manual of Mental Disorders (4th edn, text revision; DSMIV-TR) Washington, DC.

Barabasi AL, Albert R (1999). Emergence of scaling in random networks. Science 286: 509-512.

Barabási AL, Oltvai ZN (2004). Network biology: understanding the cell's functional organization. Nat Rev Genet 5: 101-113. This article reviews the present knowledge of the design principles for the structure and system-scale function of cellular networks that provides an insight that the architectural features of molecular interaction networks within a cell are shared by other complex systems such as the society.

Bayes A, Grant SG (2009). Neuroproteomics: understanding the molecular organization and complexity of the brain. Nat Rev Neurosci 10: 635-646.

Berger SI, Posner JM, Ma'ayan A (2007). Genes2Networks: connecting lists of gene symbols using mammalian protein interactions databases. BMC Bioinformatics 8: 372 This paper describes Genes2Networks, a web-based software that can help experimental biologists to interpret lists of genes and proteins by finding relationships between them and predicting additional genes or proteins that may play key roles in common pathways.

Berland D, Rodgers P (2012). Rational use of opioids for management of chronic nonterminal pain. Am Fam Physician 86: 252-258.

Brun C, Herrmann C, Guénoche A (2004). Clustering proteins from interaction networks for the prediction of cellular functions. BMC Bioinformatics 5: 95.

Bu Q, Yang Y, Yan G, Hu Z, Hu C, Duan J et al. (2012). Proteomic analysis of the nucleus accumbens in rhesus monkeys of morphine dependence and withdrawal intervention. J Proteomics 75: 1330-1342. This paper describes the characterization of morphine-withdrawal-mediated changes in protein profiles in the ventral striatum in rhesus monkeys

Calignano A, Moncada S, Di Rosa M (1991). Endogenous nitric oxide modulates morphine-induced constipation. Biochem Biophys Res Commun 181: 889-893.

Carlin RK, Grab DJ, Cohen RS, Siekevitz P (1980). Isolation and characterization of postsynaptic densities from various brain regions: enrichment of different types of postsynaptic densities. J Cell Biol 86: 831-845.

Chao J, Nestler EJ (2004). Molecular neurobiology of drug addiction. Annu Rev Med 55: 113-132. This review focuses on a small number of wellcharacterized molecules and underlying mechanisms that have been shown to contribute to certain features of drug addiction.

Cheng D, Hoogenraad CC, Rush J, Ramm E, Schlager MA, Duong DM et al. (2006). Relative and absolute quantification of postsynaptic density proteome isolated from rat forebrain and cerebellum. Mol Cell Proteomics 5: 1158-1170.
Cho KO, Hunt CA, Kennedy MB (1992). The rat brain postsynaptic density fraction contains a homolog of the Drosophila disc-large tumor suppressor protein. Neuron 9: 929-942.

Cohen RS, Blomberg F, Berzins K, Siekevitz P (1977). The structure of postsynaptic densities isolated from dog cerebral cortex. I. Overall morphology and protein composition. J Cell Biol 74: 181-203.

Collins MO, Husi H, Yu L, Brandon JM, Anderson CN, Blackstock WP et al. (2006). Molecular characterization and comparison of the components and multiprotein complexes in the postsynaptic proteome. J Neurochem 97: 16-23.

Cotman CW, Banker G, Churchill L, Taylor D (1974). Isolation of postsynaptic densities from rat brain. J Cell Biol 63: 441-455.

Dosemeci A, Tao-Cheng JH, Vinade L, Jaffe H (2006). Preparation of postsynaptic density fraction from hippocampal slices and proteomic analysis. Biochem Biophys Res Commun 339: 687-694.

Duman RS, Tallman JF, Nestler EJ (1988). Acute and chronic opiate-regulation of adenylate cyclase in brain: specific effects in locus coeruleus. J Pharmacol Exp Ther 246: 1033-1039.

Faber ES, Sah P (2004). Opioids inhibit lateral amygdala pyramidal neurons by enhancing a dendritic potassium current. J Neurosci 24: 3031-3039.

Farrell M (1994). Opiate withdrawal. Addiction 89: 1471-1475.

Fernandez E, Collins MO, Uren RT, Kopanitsa MV, Komiyama NH, Croning MD et al. (2009). Targeted tandem affinity purification of PSD-95 recovers core postsynaptic complexes and schizophrenia susceptibility proteins. Mol Syst Biol 5 269

Fioravante D, Liu RY, Byrne JH (2008). The ubiquitin-proteasome system is necessary for long-term synaptic depression in Aplysia. J Neurosci 28: 10245-10256.

Granados-Soto V, Kalcheva I, Hua X, Newton A, Yaksh TL (2000). Spinal PKC activity and expression: role in tolerance produced by continuous spinal morphine infusion. Pain 85: 395-404.

Grant SG (2003). Synapse signalling complexes and networks: machines underlying cognition. BioEssays 25: 1229-1235. This article explores the idea that the postsynapse functions as a molecular machine consisting of $\sim 100$ proteins organized into a network and that the network properties of these complexes may explain many of the features of neuronal plasticity and cognition.

Hajós F (1975). An improved method for the preparation of synaptosomal fractions in high purity. Brain Res 93: 485-489.

Hartwell LH, Hopfield JJ, Leibler S, Murray AW (1999). From molecular to modular cell biology. Nature 402: C47-C52.

Hegde AN, Goldberg AL, Schwartz JH (1993). Regulatory subunits of CAMPdependent protein kinases are degraded after conjugation to ubiquitin: a molecular mechanism underlying long-term synaptic plasticity. Proc Natl Acad Sci USA 90: 7436-7440.

Hsia JA, Moss J, Hewlett EL, Vaughan M (1984). ADP-ribosylation of adenylate cyclase by pertussis toxin. Effects on inhibitory agonist binding. J Biol Chem 259: 1086-1090.

Husi H, Ward MA, Choudhary JS, Blackstock WP, Grant SG (2000). Proteomic analysis of NMDA receptor-adhesion protein signaling complexes. Nat Neurosci 3: 661-669.

Jenkins SL, Ma'ayan A (2013). Systems pharmacology meets predictive, preventive, personalized and participatory medicine. Pharmacogenomics 14: 119-122.

Jeong H, Tombor B, Albert R, Oltvai ZN, Barabási AL (2000). The large-scale organization of metabolic networks. Nature 407: 651-654.

Jordan BA, Devi LA (1999). G-protein-coupled receptor heterodimerization modulates receptor function. Nature 399: 697-700.

Jordan BA, Fernholz BD, Boussac M, Xu C, Grigorean G, Ziff EB et al. (2004). Identification and verification of novel rodent postsynaptic density proteins. Mol Cell Proteomics 3: 857-871.

Kelly PT, McGuinness TL, Greengard P (1984). Evidence that the major postsynaptic density protein is a component of a Ca2 +/calmodulin-dependent protein kinase. Proc Natl Acad Sci USA 81: 945-949.

Kennedy MB, Bennett MK, Erondu NE (1983). Biochemical and immunochemical evidence that the 'major postsynaptic density protein' is a subunit of a calmodulin-dependent protein kinase. Proc Natl Acad Sci USA 80: 7357-7361.

Kim SI, Voshol H, van Oostrum J, Hastings TG, Cascio M, Glucksman MJ (2004). Neuroproteomics: expression profiling of the brain's proteomes in health and disease. Neurochem Res 29: 1317-1331.

Kim SY, Chudapongse N, Lee SM, Levin MC, Oh JT, Park HJ et al. (2004). Proteomic analysis of phosphotyrosyl proteins in the rat brain: effect of butorphanol dependence. J Neurosci Res 77: 867-877.

Kim SY, Chudapongse N, Lee SM, Levin MC, On JT, Park HJ et al. (2005). Proteomic analysis of phosphotyrosyl proteins in morphine-dependent rat brains. Brain Res Mol Brain Res 133: 58-70. 
Klemmer P, Smit AB, Li KW (2009). Proteomics analysis of immuno-precipitated synaptic protein complexes. J Proteomics 72: 82-90.

Law PY, Wong YH, Loh HH (2000). Molecular mechanisms and regulation of opioid receptor signaling. Annu Rev Pharmacol Toxicol 40: 389-430.

Li KW, Hornshaw MP, Van Der Schors RC, Watson R, Tate S, Casetta B et al. (2004). Proteomics analysis of rat brain postsynaptic density. Implications of the diverse protein functional groups for the integration of synaptic physiology. J Biol Chem 279: 987-1002.

Li KW, Jimenez CR, van der Schors RC, Hornshaw MP, Schoffelmeer AN, Smit AB (2006). Intermittent administration of morphine alters protein expression in rat nucleus accumbens. Proteomics 6: 2003-2008

Li Q, Zhao X, Zhong LJ, Yang HY, Wang Q, Pu XP (2009). Effects of chronic morphine treatment on protein expression in rat dorsal root ganglia. Eur $J$ Pharmacol 612: 21-28.

Li Y, Kolb B, Robinson TE (2003). The location of persistent amphetamine-induced changes in the density of dendritic spines on medium spiny neurons in the nucleus accumbens and caudate-putamen. Neuropsychopharmacology 28 1082-1085.

Lin X, Wang Q, Cheng Y, Ji J, Yu LC (2011). Changes of protein expression profiles in the amygdala during the process of morphine-induced conditioned place preference in rats. Behav Brain Res 221: 197-206.

Lovinger DM (2010). Neurotransmitter roles in synaptic modulation, plasticity and learning in the dorsal striatum. Neuropharmacology 58: 951-961.

Lovinger DM, Partridge JG, Tang KC (2003). Plastic control of striatal glutamatergic transmission by ensemble actions of several neurotransmitters and targets for drugs of abuse. Ann NY Acad Sci 1003: 226-240.

Ma'ayan A, Jenkins SL, Neves S, Hasseldine A, Grace E, Dubin-Thaler B et al. (2005). Formation of regulatory patterns during signal propagation in a Mammalian cellular network. Science 309: 1078-1083. This article describes a model of hippocampal signaling pathways and cellular machines developed using graph theory-inspired methods..

Meyer U (2008). The history of antitussive and expectorants. Pharm Unserer Zeit 37: 450-456

Milo R, Shen-Orr S, Itzkovitz S, Kashtan N, Chklovskii D, Alon U (2002). Network motifs: simple building blocks of complex networks. Science 298 824-827. This paper describes the use of an algorithm for detecting network motifs consisting of recurring and significant patterns of interconnections.

Minneman KP, Iversen IL (1976). Enkephalin and opiate narcotics increase cyclic GMP accumulation in slices of rat neostriatum. Nature 262: 313-314.

Moron JA, Abul-Husn NS, Rozenfeld R, Dolios G, Wang R, Devi LA (2007). Morphine administration alters the profile of hippocampal postsynaptic densityassociated proteins: a proteomics study focusing on endocytic proteins. $\mathrm{Mol}$ Cell Proteomics 6: 29-42. This article describes the use of subcellular fractionation and differential isotopic labeling and mass spectrometry to identify morphine-mediated changes in the abundance of proteins at the hippocampal postsynpatic density.

Nestler EJ (1996). Under siege: the brain on opiates. Neuron 16: 897-900.

Nestler EJ (2001). Molecular basis of long-term plasticity underlying addiction. Nat Rev Neurosci 2: 119-128.

Nestler EJ (2004). Historical review: molecular and cellular mechanisms of opiate and cocaine addiction. Trends Pharmacol Sci 25: 210-218.

Okada K, Kanaya S, Asai K (2005). Accurate extraction of functional associations between proteins based on common interaction partners and common domains. Bioinformatics 21: 2043-2048.

Patel VJ, Thalassinos K, Slade SE, Connolly JB, Crombie A, Murrell JC et al. (2009). A comparison of labeling and label-free mass spectrometry-based proteomics approaches. J Proteome Res 8: 3752-3759.

Peng J, Kim MJ, Cheng D, Duong DM, Gygi Sp, Sheng M (2004). Semiquantitative proteomic analysis of rat forebrain postsynaptic density fractions by mass spectrometry. J Biol Chem 279: 21003-21011.

Phillips GR, Huang JK, Wang Y, Tanaka H, Shapiro L, Zhang W (2001). The presynaptic particle web: ultrastructure, composition, dissolution and reconstitution. Neuron 32: 63-77.

Phillips GR, Florens L, Tanaka H, Khaing ZZ, Fidler L, Yates JR 3rd et al. (2005). Proteomic comparison of two fractions derived from the transsynaptic scaffold. J Neurosci Res 81: 762-775.

Pocklington AJ, Cumiskey M, Armstrong JD, Grant SG (2006). The proteomes of neurotransmitter receptor complexes form modular networks with distributed functionality underlying plasticity and behaviour. Mol Syst Biol 2: 2006.0023 This article presents an integrated analysis of molecular organization, signal transduction, and physiology of a neurotransmitter signaling complex.

Prokai L, Zharikova AD, Stevens SM Jr (2005). Effect of chronic morphine exposure on the synaptic plasma-membrane subproteome of rats: a quantitative protein profiling study based on isotope-coded affinity tags and liquid chromatography/ mass spectrometry. J Mass Spectrom 40: 169-175.

Ramos-Ortolaza DL, Bushlin I, Abul-Husn N, Annangudi SP, Sweedler J, Devi LA (2010). Quantitative neuroproteomics of the synapse. Methods Mol Biol 615: 227-246. This report describes the detailed methodology invovled in the isolation of sucellular components as well as differential isotopic labeling techniques, which have been found to be useful in the neuroproteomic analysis of the synapse.

Robinson TE, Kolb B (1997). Persistent structural modifications in nucleus accumbens and prefrontal cortex neurons produced by previous experience with amphetamine. J Neurosci 17: 8491-8497.

Robinson TE, Kolb B (1999). Alterations in the morphology of dendrites and dendritic spines in the nucleus accumbens and prefrontal cortex following repeated treatment with amphetamine or cocaine. Eur J Neurosci 11: 15981604

Robinson TE, Kolb B (1999). Morphine alters the structure of neurons in the nucleus accumbens and neocortex of rats. Synapse 33: 160-162. This is an elegant study that describes morphine administration-induced changes in the synaptic morphology.

Robinson TE, Kolb B (2004). Structural plasticity associated with exposure to drugs of abuse. Neuropharmacology 47: 33-46.

Russo SJ, Dietz DM, Dumitriu D, Morrison JH, Malenka RC, Nestler EJ (2010). The addicted synapse: mechanisms of synaptic and structural plasticity in nucleus accumbens. Trends Neurosci 33: 267-276. This review discusses the emerging and paradoxical data regarding the drug-induced changes in dendritic spines.

Samanta MP, Liang S (2003). Predicting protein functions from redundancies in arge-scale protein interaction networks. Proc Natl Acad Sci USA 100 12579-12583.

Satoh K, Takeuchi M, Oda Y, Deguchi-Tawarada M, Sakamoto Y, Matsubara K et al. (2002). Identification of activity-regulated proteins in the postsynaptic density fraction. Genes Cells 7: 187-197.

Schrimpf SP, Meskenaite V, Brunner E, Rutishauser D, Walther P, Eng J et al. (2005). Proteomic analysis of synaptosomes using isotope-coded affinity tags and mass spectrometry. Proteomics 5: 2531-2541.

Sharan R, Ulitsky I, Shamir R (2007). Network-based prediction of protein function. Mol Sys Biol 3: 88

Shui HA, Ho ST, Wang JJ, Wu CC, Lin CH, Tao YX et al. (2007). Proteomic analysis of spinal protein expression in rats exposed to repeated intrathecal morphine injection. Proteomics 7: 796-803. This study describes the spinal cord protein expression changes in rat spinal cord following repreated intrathecal morphine injection

Song Z, Guo Q, Zhang J, Li M, Liu C, Zou W (2012). Proteomic analysis of PKCgamma-related proteins in the spinal cord of morphine-tolerant rats. PLoS One 7: e42068.

Spirin V, Mirny LA (2003). Protein complexes and functional modules in molecular networks. Proc Natl Acad Sci USA 100: 12123-12128. This article uses computational techniques for the exploration of molecular networks on the meso-scale level and shows that using these algorithms complexes and modules of all sizes including transient complexes and complexes of low stoichiometry.

Stevens SM Jr, Zharikova AD, Prokai L (2003). Proteomic analysis of the synaptic plasma membrane fraction isolated from rat forebrain. Brain Res Mol Brain Res 117: 116-128.

Suder P, Bodzon-Kulakowska A, Mak P, Bierczynska-Krzysik A, Daszykowski M, Walczak B et al. (2009). The proteomic analysis of primary cortical astrocyte cell culture after morphine administration. J Proteome Res 8: 46334640

Tan R, Zou D, Chang Y (2010). Proteomic analysis of morphine rabbit myocardium with matrix-assisted laser desorption/ionization time-offlight mass spectrometry. Zhong Nan Da Xue Xue Bao Yi Xue Ban 35 607-611.

Taussig R, Iniguez-Lluhi JA, Gllman AG (1993). Inhibition of adenylyl cyclase by Gi alpha. Science 261: 218-221.

Taylor IW, Wrana JL (2012). Protein interaction networks in medicine and disease. Proteomics 12: 1706-1716.

Terwilliger RZ, Beitner-Johnson D, Sevarino KA, Crain SM, Nestler EJ (1991) A general role for adaptations in G-proteins and the cyclic AMP system in mediating the chronic actions of morphine and cocaine on neuronal function. Brain Res 548: 100-110.

Wagner A, Fell DA (2001). The small world inside large metabolic networks. Proc Biol Sci 268: 1803-1810.

Walikonis RS, Jensen ON, Mann M, Provance DW Jr, Mercer JA, Kennedy MB (2000). Identification of proteins in the postsynaptic density fraction by mass spectrometry. J Neurosci 20: 4069-4080. 
Wang XJ, Yu J, Wong SH, Cheng AS, Chan FK, Ng SS et al. (2013). A novel crosstalk between two major protein degradation systems: Regulational of proteasomal activity by autophagy. Autophagy $\mathbf{1 1}$, (e-pub ahead of print).

Watts DJ, Strogatz SH (1998). Collective dynamics of 'small-world' networks. Nature 393: 440-442.

Wei QH, Wu N, Bian JM, Chen Y, Su RB, Li J (2013). Involvement of hippocampal phosphatidylethanolamine-binding protein in morphine dependence and withdrawal. Addict Biol 18: 230-240.

Wolters DA, Washburn MP, Yates JR 3rd (2001). An automated multidimensional protein identification technology for shotgun proteomics. Anal Chem 73: 5683-5690.

Wu K, Carlin R, Siekevitz P (1986). Binding of L-[3H]glutamate to fresh and frozen synaptic membrane and postsynaptic density fractions isolated from cerebral cortex and cerebellum of fresh or frozen canine brain. J Neurochem 46: 831-841.
Yang L, Sun ZS, Zhu YP (2007). Proteomic analysis of rat prefrontal cortex in three phases of morphine-induced conditioned place preference. J Proteome Res 6: 2239-2247.

Yoshimura Y, Yamauchi T (1997). Phosphorylation-dependent revesible association of $\mathrm{Ca}+2 / \mathrm{calmodulin}$-dependent protein kinase II with the postsynaptic densities. J Biol Chem 272: 26354-26359.

Yoshimura Y, Yamauchi Y, Shinkawa T, Taoka M, Donai H, Takahashi N et al. (2004). Molecular constituents of the postsynaptic density fraction revealed by proteomic analysis using multidimensional liquid chromatography-tandem mass spectrometry. J Neurochem 88: 759-768.

Zeitz KP, Malmberg AB, Gilbert H, Basbaum Al (2001). Reduced development of tolerance to the analgesic effects of morphine and clonidine in PKC gamma mutant mice. Pain 94: 245-253. 